\title{
Selectivity of Sample Preparation by Micro Carbon Residue Method with Heat Transfer Fluids
}

\author{
Jianhua Yang ${ }^{1}$, Jingmiao $\mathrm{Li}^{2}$, Dong $\mathrm{Jin}^{3}$ and Linyuan Guo ${ }^{1 *}$ \\ ${ }^{1}$ China Special Equipment Inspection and Research Institute, Beijing \\ ${ }^{2}$ China Special Equipment Inspection and Research Institute, Beijing \\ ${ }^{3}$ China Special Equipment Inspection and Research Institute, Beijing
}

\begin{abstract}
In heat transfer fluids, the carbon residue value is an indicator that provides its relative coking tendency. The micro carbon residue method is widely used because of the simple and convenient operation procedures and low pollution. However, when the carbon residue value is less than $0.1 \%$, the sample needs to be prepared and then tested in the furnace. Therefore, this article aims at the measurement of carbon residue by the heat transfer fluids micro method. The heat transfer fluids is classified according to the product type and the maximum allowed temperature. The sample is prepared by pretreatment. In the method for determining micro carbon residue, whether the sample prepared by pretreatment is selective.
\end{abstract}

\section{Introduction}

Heat transfer fluids is a general term for organic materials that can be used as an indirect heat transfer medium including heat transfer fluids, hot oils, organic heat transfer carriers, heating media, etc.[1]. According to the state of use, it can be divided into unused heat transfer fluids and in-use heat transfer fluids. According to the product type, the unused heat transfer fluids can be divided into refined heat transfer fluids, ordinary synthetic heat transfer fluids and synthetic heat transfer fluids with special high thermal stability. Among them, the general synthetic type and the synthetic type with special high thermal stability are divided according to the maximum permitted bulk temperature, and the two are collectively called the synthetic type. The synthetic type is different from the mineral type. The former is produced by a chemical synthesis process, and the latter is a distillate obtained by distillation and refining of petroleum.

At present, heat transfer fluids can be widely used in many fields such as petrochemicals, wood processing, automobiles, and clothing manufacturing. They are inseparable from the advantages of continuous use under low pressure and high temperature, but cracking and degradation will also occur during this process, making the heat transfer fluids deteriorates and forms coking in the pipeline to form carbon residue[2].

The carbon residue value is used to estimate the general tendency of various petroleum products to form carbonaceous sediments after evaporation and thermal cracking under high temperature conditions to provide a relative tendency of petroleum products to generate coke[3]. The main components that easily form carbon residue are mostly colloids, asphaltenes, polycyclic aromatic hydrocarbons, and non-volatile additives in the sample[4-6].

The determination methods of carbon residue in petroleum products include conradson method, LAN's method, electric furnace method and micro method, and they are all widely used. For heat transfer fluids, conradson method (GB/T 268-1987 "Petroleum productsDetermination of carbon residue- Conradson method"), electric furnace method (SH/T 0170-1992 (2000) "Petroleum products- Determination of carbon residueElectric furnace method)" and micro method (GB/T 17144-1997 "Petroleum products- Determination of carbon residue- Micro method") to detect the carbon residue value. The conradson method is the arbitration method for the determination of carbon residue in heat transfer fluids. However, the sample is directly heated on an open flame, manual operation is required throughout the whole process, which not only causes greater environmental pollution, but also greater harm to the human body of the experimental personnel, and will also cause certain artificial error. Therefore, the electric furnace method and the micro method are generally used to determine the carbon residue in the heat transfer fluids. However, compared with the electric furnace method, which needs to ignite the sample steam after the sample was heated, the micro method has the advantages of high degree of automation and low pollution.

Although the micro method does not require the person to manually ignite to observe the flame and the state of the sample, it avoids manual errors in this regard and reduces environmental pollution. However, the direct measurement of the sample into the furnace test requires a measurement range of $0.10 \%(\mathrm{~m} / \mathrm{m}) \sim 30.0 \%(\mathrm{~m} / \mathrm{m})$, and the measurement result is equivalent to conradson residual carbon. For samples with a carbon residue value of less

*Corresponding author's e-mail: hxfxzx2017@126.com 
than $0.10 \%(\mathrm{~m} / \mathrm{m})$, the samples need to be prepared before they can be tested in the furnace. As for the unused heat transfer fluids, according to the requirements in Table 2 of GB 23971-2009 "Heat transfer fluids", the carbon residue (mass fraction) is not more than $0.05 \%$. It can be seen that all the unused heat transfer fluids need to prepare samples when using micro method to detect the carbon residue. But it not only consumes time and energy, but also consumes too many samples. Therefore, in this paper, $10 \%(\mathrm{~V} / \mathrm{V})$ distillation residue was prepared according to sample pretreatment, and further experimental comparison is made on the detection of distillation residue and untreated samples, so as to analyze whether the sample pretreatment was selectable in micro method measurement of carbon residue.

Common unused heat transfer fluids can be divided into $280^{\circ} \mathrm{C}, 300^{\circ} \mathrm{C}, 310^{\circ} \mathrm{C}, 320^{\circ} \mathrm{C}, 330^{\circ} \mathrm{C}, 340^{\circ} \mathrm{C}, 350^{\circ} \mathrm{C}$ and $400^{\circ} \mathrm{C}$, according to the maximum permitted bulk temperature, of which the mineral type heat transfer fluids involves $280^{\circ} \mathrm{C}, 300^{\circ} \mathrm{C}, 310^{\circ} \mathrm{C}$ and $320^{\circ} \mathrm{C}$, the synthetic type heat transfer fluids involves $300^{\circ} \mathrm{C}, 310^{\circ} \mathrm{C}, 320^{\circ} \mathrm{C}$, $330{ }^{\circ} \mathrm{C}, 340{ }^{\circ} \mathrm{C}, 350^{\circ} \mathrm{C}$ and $400{ }^{\circ} \mathrm{C}$. Therefore, the experimental data can be classified as the comparison of the carbon residue value between the synthetic heat transfer fluids and the mineral heat transfer fluids.

\section{Experiment}

\subsection{Material}

Nitrogen, purity $99.999 \%$; Clean brown glass bottle (20ml).

\subsection{Instruments}

Shanghai Tanaka ACR-M3 automatic micro carbon residue tester, equipped with sample tube, sample rack, waste liquid bottle, tweezers etc.; Optidist automatic atmospheric distillation analyzer, equipped with flask, measuring cylinder, heating plate, cork etc.; Mettler Toledo analytical balance, measuring range $220 \mathrm{~g}$, sensitivity $0.1 \mathrm{mg}$.

\subsection{Sample Preparation}

Assuming that the carbon residue value of the test sample is lower than $0.10 \%(\mathrm{~m} / \mathrm{m})$, according to the GB/T 17144 1997 "Petroleum products- Determination of carbon residue- Micro method", sample pretreatment is required. The specific pretreatment process is as follows:

2.3.1. Accurately measure $100 \mathrm{~mL}$ sample into $125 \mathrm{~mL}$ or $200 \mathrm{~mL}$ distillation flask, remove the temperature line and replace it with another cover, fix it on the instrument, and select $50 \mathrm{~mm}$ or $38 \mathrm{~mm}$ heating plate;

2.3.2. Before using the automatic atmospheric distillation apparatus, it is necessary to set the temperature of the heating plate (the instrument's limit heating temperature $-10^{\circ} \mathrm{C}$ ) and the heating stop volume $(89 \mathrm{~mL})$;

2.3.3. When the heating stops, observe the volume of liquid in the receiving measuring cylinder. When it reaches $90 \mathrm{~mL}$, change a clean and dry $20 \mathrm{ml}$ brown glass bottle to collect the remaining reflux liquid,and fully mix it with the remaining samples in the flask to obtain $10 \%(\mathrm{~V} / \mathrm{V})$ distillation residue.

\subsection{Weighing and recording quality $m_{1}$}

In order to reduce the weighing error, the clean sample tube matching with the micro carbon residue tester with a capacity of $4 \mathrm{~mL}$ is clamps with tweezers, and the mass $\mathrm{m}_{1}$ of the empty tube was recorded, accurate to $0.1 \mathrm{mg}$.

\subsection{Weighing and recording quality $m_{2}$}

$3.00 \mathrm{~g} \pm 0.50 \mathrm{~g}$ of the sample prepared in 2.3 .3 was taken and loaded into the weighed empty tube to avoid hanging the sample wall. The mass $m_{2}$ of the empty tube and the sample was recorded to an accurate level of $0.1 \mathrm{mg}$.

\subsection{The weighed sample is put into the micro carbon residue tester along with the sample rack for carbon residue detection:}

The partial pressure of the nitrogen bottle is controlled at $2.5 \mathrm{MPa} \pm 0.1 \mathrm{MPa}$, and the pressure regulator on the instrument controls the pressure at $147 \mathrm{KPa}$. The nitrogen flow rate was $150 \mathrm{~mL} / \mathrm{min}$ before the start of the test. When the test started, the flow rate was purged at $600 \mathrm{~mL} / \mathrm{min}$ for $10 \mathrm{~min}$. At this time, the test temperature rose to $100^{\circ} \mathrm{C}$; after that, the nitrogen flow rate was reduced to $150 \mathrm{~mL} / \mathrm{min}$ and heated in stages. After 47 minutes, the furnace temperature reached $500^{\circ} \mathrm{C}$; finally purged with the current nitrogen flow, the furnace temperature was stabilized at $500^{\circ} \mathrm{C} \pm 2^{\circ} \mathrm{C}$ for 15 minutes; after the end, the purge and cooling were continued with a nitrogen flow of $600 \mathrm{~mL} / \mathrm{min}$, and the instrument temperature program was closed after 95 minutes.

\subsection{Weighing and recording quality $m_{3}$}

Until the temperature drops below $250^{\circ} \mathrm{C}$, take out the sample rack and put it into a desiccator to cool to room temperature. Weigh the mass of the sample tube after the test and record the mass $m_{3}$ to the nearest $0.1 \mathrm{mg}$. If the sample splashes and blisters, this test is invalid and needs to be repeated. 
2.8. According to formula (1), the carbon residue value of $10 \%(\mathrm{~V} / \mathrm{V})$ distillation residue can be calculated, $\%(\mathrm{~m} / \mathrm{m})[7]$ :

$$
X=\frac{m_{3}-m_{1}}{m_{2}-m_{1}} \times 100
$$

Then convert to the original sample carbon residue value according to formula (2) $X^{\prime}$ :

$$
X^{\prime}=\frac{X}{10}
$$

Then calculate the repeatability $r$ according to formula (3) to ensure the credibility of the data [7]:

$$
r=0.0770 X^{\prime(2 / 3)}
$$

The final total carbon residue is the sum of the ash content or nonvolatile additive content in the sample and the carbon residue value.

\section{Comparison of experimental results}

\subsection{Synthetic heat transfer fluids with special high thermal stability}

The maximum permitted bulk temperature of the samples at $330^{\circ} \mathrm{C}, 340^{\circ} \mathrm{C}, 350^{\circ} \mathrm{C}$ and $400^{\circ} \mathrm{C}$, can be prepared

\begin{tabular}{|c|c|c|c|c|c|}
\hline \multirow{2}{*}{ product type } & \multirow{2}{*}{ sample number } & \multirow{2}{*}{$\begin{array}{l}\text { thermal stability test } \\
\text { temperature } /{ }^{\circ} \mathrm{C}\end{array}$} & \multicolumn{3}{|c|}{ carbon residue value of original sample $/ \%$} \\
\hline & & & \multicolumn{2}{|c|}{ parallel measured value } & \multirow{2}{*}{$\frac{\text { mean }}{0.0013}$} \\
\hline & 1 & & 0.0013 & 0.0013 & \\
\hline & 2 & 300 & 0.0057 & 0.0057 & 0.0057 \\
\hline & 3 & & 0.0450 & 0.0442 & 0.0446 \\
\hline & 4 & & 0.0013 & 0.0013 & 0.0013 \\
\hline & 5 & 310 & 0.0013 & 0.0013 & 0.0013 \\
\hline & 6 & & 0.0040 & 0.0033 & 0.0036 \\
\hline & 7 & & 0.0013 & 0.0013 & 0.0013 \\
\hline \multirow[t]{8}{*}{ synthetic type } & 8 & 320 & 0.0013 & 0.0013 & 0.0013 \\
\hline & 9 & & 0.0023 & 0.0020 & 0.0022 \\
\hline & 10 & & 0.0013 & 0.0013 & 0.0013 \\
\hline & 11 & 330 & 0.0013 & 0.0013 & 0.0013 \\
\hline & 12 & & 0.0030 & 0.0030 & 0.0030 \\
\hline & 13 & & 0.0013 & 0.0013 & 0.0013 \\
\hline & 14 & 340 & 0.0024 & 0.0018 & 0.0021 \\
\hline & 15 & & 0.0040 & 0.0043 & 0.0042 \\
\hline
\end{tabular}
according to experiment $2.310 \%(\mathrm{~V} / \mathrm{V})$ distillation residue,

Table1. Carbon residue values of synthetic heat transfer fluids and mineral heat transfer fluids and the calculated carbon residue value is less than $0.01 \%$, as shown in Table 1.

\subsection{Ordinary synthetic heat transfer fluids}

The samples with the maximum permitted bulk temperatures of $310^{\circ} \mathrm{C}$ and $320^{\circ} \mathrm{C}$ can also be prepared with $10 \%(\mathrm{~V} / \mathrm{V})$ distillation residue according to experiment 2.3 , and the calculated carbon residue value is lower than $0.01 \%$, as shown in Table 1 .

The maximum permitted bulk temperature is $300^{\circ} \mathrm{C}$. Some samples can prepare $10 \%(\mathrm{~V} / \mathrm{V})$ distillation residue according to experiment 2.3 , and the calculated carbon residue value is lower than $0.05 \%$, as shown in Table 1 .

\subsection{Refined mineral heat transfer fluids}

The samples with the maximum permitted bulk temperature of $280^{\circ} \mathrm{C}$ and $300^{\circ} \mathrm{C}$, two thirds of the samples can prepare $10 \%(\mathrm{~V} / \mathrm{V})$ distillation residue according to experiment 2.3 , and the calculated carbon residue value is mostly lower than $0.01 \%$, all lower than $0.05 \%$, as shown in Table 1 .

The samples with the maximum permitted bulk temperatures of $310^{\circ} \mathrm{C}$ and $320^{\circ} \mathrm{C}$, three quarters of the samples can prepare $10 \%(\mathrm{~V} / \mathrm{V})$ distillation residue according to experiment 2.3 , and the calculated carbon residue value is mostly less than $0.01 \%$, all less than $0.05 \%$, as shown in Table 1 . 


$\begin{array}{cllll}16 & & 0.0013 & 0.0013 & 0.0013 \\ 17 & 350 & 0.0033 & 0.0037 & 0.0035 \\ 19 & & 0.0050 & 0.0037 & 0.0044 \\ 20 & 400 & 0.0013 & 0.0013 & 0.0013 \\ 21 & & 0.0013 & 0.0013 & 0.0013 \\ 22 & & 0.0013 & 0.0013 & 0.0013 \\ 23 & 280 & 0.0013 & 0.0013 & 0.0013 \\ 24 & & 0.0057 & 0.0055 & 0.0056 \\ 25 & & 0.0107 & 0.0110 & 0.0108 \\ 26 & 300 & 0.0013 & 0.0013 & 0.0013 \\ 27 & & 0.0070 & 0.0074 & 0.0072 \\ 28 & & 0.0325 & 0.0331 & 0.0328 \\ 29 & 310 & 0.0013 & 0.0013 & 0.0013 \\ 30 & & 0.0013 & 0.0013 & 0.0013 \\ 31 & & 0.0013 & 0.0013 & 0.0013 \\ 32 & 320 & 0.0013 & 0.0013 & 0.0013 \\ 33 & & 0.0017 & 0.0017 & 0.0017 \\ & & 0.0459 & 0.0443 & 0.0451\end{array}$

\subsection{Comparison before and after sample} processing

In addition, carbon residue test was conducted between

Table2. Sample weighing and carbon residue value

\begin{tabular}{llccccc}
\multicolumn{7}{c}{ Table2. Sample weighing and carbon residue value } \\
\hline $\begin{array}{c}\text { sample } \\
\text { number }\end{array}$ & sample status & $\mathrm{m}_{1} / \mathrm{g}$ & $\mathrm{m}_{2} / \mathrm{g}$ & $\mathrm{m}_{3} / \mathrm{g}$ & $\begin{array}{c}\text { carbon } \\
\text { residue } \\
\text { value } / \%\end{array}$ & $\begin{array}{c}\text { original } \\
\text { carbon } \\
\text { residue } \\
\text { value } / \%\end{array}$ \\
\hline \multirow{3}{*}{34} & $\begin{array}{l}\text { sample } \\
\text { preparation }\end{array}$ & 12.9874 & 15.9724 & 12.9971 & 0.3250 & 0.0325 \\
& 12.2998 & 15.2874 & 12.3097 & 0.3314 & 0.0331 \\
& $\begin{array}{l}\text { no sample } \\
\text { preparation }\end{array}$ & 12.2823 & 18.2883 & 12.2840 & $/$ & 0.0283 \\
& 14.3189 & 20.3193 & 14.3209 & $/$ & 0.0333 \\
35 & $\begin{array}{l}\text { sample } \\
\text { preparation }\end{array}$ & 14.3804 & 17.3824 & 14.3939 & 0.4497 & 0.0450 \\
& $\begin{array}{l}\text { no sample } \\
\text { preparation }\end{array}$ & 14.4176 & 17.4061 & 14.4308 & 0.4417 & 0.0442 \\
& $\begin{array}{l}\text { sample } \\
\text { preparation }\end{array}$ & 14.3925 & 17.3985 & 14.3938 & $/$ & 0.0433 \\
& 14.5019 & 17.5080 & 14.5157 & 0.4591 & 0.0432 \\
& 14.5824 & 17.5863 & 14.5957 & 0.4428 & 0.0459
\end{tabular}

samples prepared and those without sample preparation but with increased amount of sample injection. The specific carbon residue data are shown in Table 2. See Table 3 for the comparison of test data of whether the sample has been pre-processed. 


\begin{tabular}{|c|c|c|c|c|c|}
\hline no sample & 14.5010 & 17.4948 & 14.5023 & I & 0.0434 \\
\hline preparation & 14.4850 & 17.4863 & 14.4861 & / & 0.0367 \\
\hline
\end{tabular}

Table3. Difference between sample preparation and no sample preparation carbon residue

\begin{tabular}{lllccc}
\hline \multirow{2}{*}{$\begin{array}{l}\text { sample } \\
\text { number }\end{array}$} & sample status & \multicolumn{2}{c}{ carbon residue, difference and repeatability of original samples/\% } \\
\cline { 3 - 5 } 34 & mean & difference & repeatability & $\begin{array}{c}\text { repeatability between } \\
\text { the two }\end{array}$ \\
\hline \multirow{2}{*}{35} & sample preparation & 0.0328 & 0.0006 & 0.0079 & 0.0077 \\
& no sample preparation & 0.0308 & 0.0050 & 0.0076 & 0.0096 \\
36 & sample preparation & 0.0446 & 0.0008 & 0.0097 & 0.0094
\end{tabular}

\section{Analysis of experimental results}

4.1. It can be seen from Table 1 that the samples with synthetic heat transfer fluids and the maximum permitted bulk temperature between $310{ }^{\circ} \mathrm{C}$ and $400{ }^{\circ} \mathrm{C}$ can effectively prepare $10 \%(\mathrm{~V} / \mathrm{V})$ distillation residue, and the carbon residue value obtained is not more than $0.05 \%$. The main components of the samples are mostly hydrogenated terphenyls, diphenyl, diphenyl and diphenyl ether, etc.

4.2. The synthetic heat transfer fluids and the maximum permitted bulk temperature at $300^{\circ} \mathrm{C}$ can be normally prepared except for some samples that cannot be effectively prepared. The carbon residue value obtained is not more than $0.05 \%$, and the main components of the samples are mostly alkyl benzene and alkane. The maximum permitted bulk temperature at $280^{\circ} \mathrm{C}$ synthetic heat transfer fluids rarely appeared and was not included in the experimental comparison.

4.3. Most of the refined mineral heat transfer fluids can effectively prepare $10 \%(\mathrm{~V} / \mathrm{V})$ distillation residue, and the carbon residue value obtained is not more than $0.05 \%$, and the main components of the samples are mostly hydrocarbon and alkyl benzene. A few hydrocarbon and alkyl benzene cannot be prepared.

4.4. Through pretreatment experiments, it was found that in the process of preparing $10 \%(\mathrm{~V} / \mathrm{V})$ distillation residue, some samples could not be distilled at the limit temperature of the atmospheric distillation apparatus, so they could not be prepared normally.

The current conradson carbon residue method and micro carbon residue method are based on ISO 6615-1983 and ISO 10370:1993, respectively. The current reference methods are updated to ISO 6615-1993 (Conradson carbon residue method) and ISO 10370-2014 (Micro carbon residue method), respectively, but these methods also do not specify what should be done when samples cannot be prepared. Electric furnace process is a reference to the former Soviet union countries standard ГОСТ 885274 , the current reference of this method has not been updated, this method has not clearly pointed out that when the sample could not be should be how to deal with.

Although the three standard methods for the determination of heat transfer fluids carbon residue all involve the preparation of $10 \%(\mathrm{~V} / \mathrm{V})$ distillation residue, it is indicated in part II of the ISO 6615-1993 method summary that for light products with more than $90 \%(\mathrm{~V} / \mathrm{V})$ distilled below $370^{\circ} \mathrm{C}$, subsequent experiments can be conducted on the residue after $90 \%(\mathrm{~V} / \mathrm{V})$ distillation[8]. It can be seen that there is no problem that samples cannot be prepared by conradson method, instead, it is the electric furnace method and the micro method. No matter what the sample composition is, the sample preparation is involved without the use of heat transfer fluids. In the case that the sample cannot be prepared, the conradson method can only be used for the test.

However, through experimental comparison, for samples that cannot be prepared, refer to ASTM:D453015 (micro carbon residual method) 6.2: appropriately increase the sample size and enter into furnace heating test directly. But at present, the determination results of this method cannot be verified to be equivalent to conradson carbon residual method[9]. The samples that can be prepared effectively and have a large carbon residue value are selected for comparison test by directly adding normal sample quantity or twice sample quantity. The values obtained are within the range of repeatability.

\section{Conclusion}

The heat transfer fluids can be selectively prepared when it is used to prepare the samples: it mainly prepares the samples with the maximum permitted bulk temperature of $280^{\circ} \mathrm{C}$ and $300^{\circ} \mathrm{C}$ for the ordinary synthetic heat transfer fluids, and the refined mineral heat transfer fluids. Ordinary synthetic heat transfer fluids with the maximum 
permitted bulk temperature of $310^{\circ} \mathrm{C}$ and $320^{\circ} \mathrm{C}$, and the synthetic heat transfer fluids with special high thermal stability can be used without pretreatment or according to the actual situation.

Some samples cannot be prepared because of many heavy components. The normal sample amount or increase the sample amount can be used directly test or choose to use the conradson carbon residue method for experiment.

\section{References}

1. GB 23971-2009 Heat transfer fluids. S.

2. Li Y., (2017) Discussion on Determination Method of Acid Value of Heat transfer fluids. J. Guangzhou Chemical Industry, 45: 18-19/41.

3. WEN P., SUN Z.H., LI S.F., MU B.Q., LI C., (2014) Teaching Reformation of Determination Experiment of Carbon Residue in Petroleum Products. J. Contemporary Chemical Industry, 43: 509-511.

4. Wang H., Wen P., (2011) Determination method of carbon residue in petroleum products. J. Modern Instruments, 17: 73-75.

5. Luo Y.D., Guo Y.C., (2007) Research on Carbon Residue in the Petroleum by Micro Determination. J. Guangdong Chemical Industry, 34: 110-114.

6. Ren F., (2006) Determination of Carbon Residue in Petroleum Products. J. Guangdong Chemical Industry, 33: 63-64/54.

7. GB/T 17144-1997 Petroleum productsDetermination of carbon residue- Micro method. S.

8. ISO 5516-1993 Petroleum products-Determination of carbon residue-Conradson meth. S.

9. ASTM:D4530-15 Standard Test Method for Determination of Carbon Residue(Micro Method). S. 